Title Page

\title{
Perplexing condition of child full immunisation in economically better off Gujarat in India: An assessment of the factors associated with it
}

First Author: Srinivas Goli, PhD (Corresponding Author) Australia India Institute (AII) NGN Research Fellow UWA Public Policy Institute University of Western Australia (UWA)

35 Stirling Highway

Perth WA 6009

Australia

Email: srinivas.goli@uwa.edu.au

$\mathrm{T}+61864882914, \mathrm{M}+6141^{`} 6271232$

\&

Assistant Professor, Population Studies

Centre for the Study of Regional Development

Room No. 102, School of Social Sciences (SSS-III)

Jawaharlal Nehru University (JNU)

New Delhi-110067

Phone No: 01126738798

The University of Western Australia (M251),

35 Stirling Highway,

6009 Perth, Australia

Email: srinivas.goli@uwa.edu.au; sirispeaks2u@gmail.com http://orcid.org/0000-0002-8481-484X

Second Author: K.S. James, PhD

Director \& Senior Professor

International Institute for Population Sciences (IIPS),

Govandi Station Road, Deonar,

Mumbai - 400088, India

Phone No: 022-42372888

Email: ksjames@iips.net; ksjames@gmail.com

Third Author: Saseendran Pallikadavath, PhD

Professor in Demography and Global Health,

Portsmouth-Brawijaya Centre for the Global Health,

Population and Policy,

University of Portsmouth, United Kingdom

Phone No: +44 (0) 2392844442

Email: sasee.pallikadavath@port.ac.uk

https://orcid.org/0000-0002-2598-9949

Fourth Author: Udaya S. Mishra, PhD

Professor, Centre for Development Studies (CDS)

Thiruvananthapuram - 695 011, Kerala, India.

Phone No: 0471- 2774222; 0471-2556026

Email: mishra@cds.ac.in 
Fifth Author: S Irudaya Rajan, PhD

Professor, Centre for Development Studies (CDS)

Thiruvananthapuram - 695 011, Kerala, India.

Phone No: 0471- 2774211; 0471 -2550 694

Email: rajan@cds.ac.in

Sixth Author: Ravi Durga Prasad, MPhil.

Project Officer (PO), UNFPA Ageing Project,

International Institute for Population Sciences (IIPS),

Govandi Station Road, Deonar,

Mumbai - 400088, India

Phone No: +91 8779742610

Email: durga.rdp20@gmail.com

https://orcid.org/0000-0002-2778-0268

Seventh Author: Pradeep S. Salve, PhD

Assistant Director,

Population Research Centre (PRC),

Dharwad, Karnataka - 580 004, India

Phone No: +919867954621

Email: pradeep8889@gmail.com

ORCID: https://orcid.org/0000-0002-6879-1246 
1 Perplexing condition of child full immunisation in economically better off

2 Gujarat in India: An assessment of the factors associated with it

3 Abstract

4 Background: Despite decent progress in Children Full Immunisation (CFI) in India during the 5 last decade, surprisingly, Gujarat, an economically more developed state, had the second-lowest coverage of CFI (50\%) in the country, lower than economically less developed states such as Bihar (62\%). Further, the proportion of children with no immunisation in Gujarat has risen from

$85 \%$ in 2005 to $9 \%$ in 2016 . This paper investigated factors associated with the low level of CFI 9 coverage in Gujarat.

Methods: The study used two types of datasets: (1) the study used information on immunisation from 7,730 children aged 12-23 months and their mothers from the fourth round of the Gujarat chapter of National Family Health Survey (NFHS 2015-16). (2) A macro (district) level data on both supply and demand-side factors of CFI are compiled from multiple sources. Bivariate and multivariate linear and logistic regression techniques were employed to identify the factors associated with CFI coverage.

Results: In Gujarat, during 2015-2016, 50\% of children aged 12 to 23 months did not receive full immunisation. The odds of receiving CFI was higher among children whose mothers had a Maternal and Child Protection (MCP) card (OR: 1.97, 95\% CI 1.48-2.60) and those who received "high" maternal health services utilisation (OR: 1.59, 95\% CI 1.10-2.26) compared to their counterparts. The odds of receiving CFI was about three times higher among the richest households (OR: 6.50, 95\% CI 3.75-11.55) compared to their counterparts in the poorer households. Macro-level analyses suggest that poverty, maternal health care, and higher-order births are defining factors of CFI coverage in Gujarat.

Conclusions: In order of importance, focusing on poverty, economic inequalities, pregnancy registration, and maternal health care services utilisation are likely to improve receiving CFI uptake in Gujarat. The disadvantageous position of urban areas and non-scheduled tribes in CFI coverage needs further investigation.

28 Keywords: Children full immunisation, Economic inequalities, Gujarat, India, Quality of maternity care, Supply and demand-side determinants 


\section{Introduction}

Vaccinations against preventable diseases for children helped eradicate smallpox and eliminate poliovirus in many countries of the world leading to improved population health [1]. Achieving Children Full Immunisation (CFI) would ensure a reduction in childhood mortality and achieve target 3.2 under the Sustainable Development Goal 3 (SDG 3). Also, CFI coverage will help enhance disease-free life years enabling the achievement of other SDGs [2], for example, SDG 1 and 2 that focus on reducing poverty and hunger.

Globally, in recent decades, there has been a rapid improvement in CFI coverage. According to United Nations, International Children's Emergency Fund (UNICEF) and World Health Organisation (WHO) estimates, countries in America, Australia, Europe, and Asia excluding south and central Asia reached almost $90 \%$ of CFI coverage by 2015 . However, the lower and middle-income (LMIC) countries in Sub-Saharan and central Africa and south and central Asia continue to have poor performance in CFI coverage with fluctuating or stagnant trends with large inequalities by income levels [2, 3, 4].

Government of India, in 1978, launched an Extended Programme of Immunisation (EPI) to increase coverage of immunisation for children and pregnant women. However, its coverage was limited to urban areas and did not include all the vaccines. To overcome these limitations, in 1985, Government of India introduced Universal Immunisation Programme (UIP). UIP included vaccines that cover 12 life-threatening diseases including BacilleCalmette-Guerin (BCG), Diptheria, Pertussis, Tetanus (DPT), Oral Polio Vaccine (OPV) and vaccinations against measles [5]. Further, the UIP added vitamin-A supplementation in 1990, Polio eradication in 1995-96, Pentavalent 1,2,3 dosage replacing DPT 1,2,3 in 2012-13, among others. To deliver these services UIP was strengthened by recruiting more healthcare personnel, training of the health personnel for immunisation, and extension of the cold chain and logistics infrastructure throughout India [5, 6]. These targeted interventions increased CFI coverage in India from 44\% in $2005-06$ to $62 \%$ in $2015-16$ [7].

However, state-wise coverage of CFI indicates that all the socio-economically better-off states, except Gujarat, have registered higher CFI coverage during 2006-2016 [7]. For example, socio-economically weaker states such as Odisha (76\%), Chhattisgarh (75\%), Jharkhand (62\%), Bihar (62\%), Uttar Pradesh (58\%), Rajasthan (55\%) and Madhya Pradesh (54\%) had registered higher CFI coverage than Gujarat (50\%) (Figure 1). The situation of Gujarat is surprising and it 
61 presents a paradoxical situation in the context of its economic development. Gujarat, which ranks

62 fifth among the states in India in terms of gross state domestic product for the financial year 2015-16 [8] recorded second-lowest CFI coverage in the country and is much below the national average of $62 \%$ [7]. Further, a comparison of the percentage of children by type of vaccination dosage, suggests that the follow-up doses in DPT and Polio vaccines drop significantly from the first dose to the third dose in Gujarat (Figure 2). A rise of just 5\% in CFI coverage in a decade (2005-06 to 2015-16) for an economically progressive state such as Gujarat invites considerable attention to study the underlying reasons for poor progress in CFI coverage and also why it has been one of the lowest in India. In fact, the number of children with no vaccination coverage in Gujarat has increased from 5\% to $9 \%$ from 2005-06 to 2015-16 (Figure 3). Given the background, the paper aims to identify the factors associated with the low level of CFI coverage in Gujarat.

\section{Materials and Methods}

\subsection{Data and sample selection}

The study used both micro and macro datasets. First, microdata from the fourth round of Indian National Family Health Survey (NFHS) conducted during 2015-16 is used to examine primarily maternal, socio-demographic factors of CFI considering children as a unit of analyses. It used the "children's file" that provides information on immunisation coverage of children between 12-23 months of age along with other information related to maternal and child health, socio-demographic characteristics of mothers and their households. The survey was conducted by the International Institute for Population Sciences (IIPS), Mumbai under the stewardship of the Ministry of Health and Family Welfare (MoHFW), Government of India. The survey was conducted in 29 states and 6 union territories covering 640 districts. Nationally, 6, 99,686 evermarried women aged 15-49 years were interviewed. The respondents were selected based on multi-level stratified sampling. A detailed methodology is provided in the NFHS national report [7].

Using data collected from Gujarat state, this paper analysed data from 22,932 ever-married women (15-49 years) and 7730 children aged 12-23 months. The survey questionnaire administered to mothers asked whether their children have received vaccinations (the definition is given in section 2.3.) and the responses were verified with the immunisation card [7]. 
For the second set of analyses, the paper used macro-level (district-level) information on both supply and demand-side factors for Gujarat. The data was compiled from the Directorate of Economics and Statistics reports of Government of Gujarat [8], Census of India [9], Rural Health Statistics reports [10], Reserve Bank of India reports [11], NFHS reports for India and Gujarat [7].

\subsection{Statistical analyses}

Statistical analyses were performed in four stages. In the first stage, descriptive statistics were carried out to understand the distributions of the selected variables. In the second stage, CFI coverage according to socio-economic and demographic characteristics was carried out. Third, the binary logistic regression model was applied to identify the factors associated with CFI. The logistic regression estimates produced results based on maximum likelihood function estimates where an odds ratio of more than one indicates the increased occurrence of events and viceversa. Finally, linear and panel data regressions were applied on macro-level datasets for Gujarat and India. The statistical expression of the logistic, linear, and panel data regressions are is widely reported in the literature, see Colin and Trivedi, 2010 [12]. The statistical analysis was performed using STATA 16 statistical software (Stata Corporation, College Station, TX, USA).

\subsection{Definition of variables}

Children Full Immmunisation (CFI) means children aged 12-23 months received one dose of BCG vaccine, which protects against tuberculosis; three doses of DPT vaccine, which protects against diphtheria, pertussis (whooping cough) and tetanus; three doses of polio vaccine; one dose of measles vaccine at any time before the survey [7]. Although, NFHS definition of CFI is not completely aligned to the latest WHO guidelines as it doesn't consider all recommended vaccinations of the WHO. However, as a part of harmonious global surveys under the aegis of Demographic and Health Survey (DHS), NFHS follows similar questionnaire tools of DHS. The Global Health Observatory of WHO considers the similar definition that DHS uses for global monitoring of CFI trends [13].

Eligibility for these immunisations are within two years of birth. To model a binary logistic regression, $\mathrm{CFI}$, a dichotomous dependent variable was constructed: whether or not children of 
age 12 to 23 months received all basic vaccinations with the response from mothers, where ' 1 ' denotes received and ' 0 ' denotes not received.

The independent variables expected to have an association with CFI were selected based on the literature [14-20]. These include: maternal health care service utilisation index; mothers' socio-economic and demographic characteristics; pregnancy registration with possession of MCP card. Following Kotelchuck [21] and Gosh [22], the maternal health care utilisation index was measured using 34 variables: key variables include antenatal care at home or institution, tests performed in at least one ANC visit, women receiving tetanus toxoid injection, child weight at birth, communicated about pregnancy complications and being visited or advised by any health worker. The full list of the variables used in the construction of maternal health care utilisation index are given in Appendix Table 1. The dimension reduction was done through Principle Component Analyses (PCA). PCA weighted factor score was generated for each woman and based on the score mothers were categorised into three categories: "low", "medium" and "high" maternal health care service utilisation. Women who have "poor" maternal health care service utilisation index were expected to have lower chances of receiving full immunisation. Other socio-economic variables used in the individual analyses include the socio-economic and demographic characteristics of women include: age, the highest level of education completed, caste (a form of social stratification characterised by endogamy, hereditary transmission of a style of life which often includes an occupation, ritual status in a hierarchy, and customary social interaction and exclusion based on cultural notions of purity and pollution), religion, wealth quintile, place of residence, birth order and birth interval and sex of the child.

The full list of the supply and demand-side variables used in the macro-level analyses are detailed in Appendix Table 2. A key supply-side defining factor is Health Infrastructure Index (HHI). HHI is constructed using the United Nations' Human Development Index (HDI) methodology [23]. The variable used for the index construction are the number of Accredited Social Health Activists (ASHAs), Sub-centres, Primary Health Centers (PHCs), and Auxiliary Nurse Midwife (ANMs) per 1000 population in each district of Gujarat. $75^{\text {th }}$ round of National Sample Survey (NSS) reports suggesting that these four major public sources together delivers a maximum proportion of CFI coverage in India [24]. The standard categorisation of the predictor variables adopted from the existing literature [14-20].

\section{Results}




\subsection{Description of the study population}

Table 1 presents the characteristics of the study population from Gujarat. The study used immunisation data from 7730 children aged between 12-23 months. Only 10\% of mothers received "high" maternal health care service utilisation. More than half of the women did not register their pregnancy with MCP cards. About 32\% of the mothers were 15-24 years of age and 29\% were aged 30 years and above. Fifty-two percent of mothers have completed secondary level education, but only $10 \%$ have higher education. Considering the birth order and birth interval combinations, $14 \%$ of children were first-order births with $<2$ years of birth interval, $17 \%$ were second-order births with $<3$ years of birth interval and $5 \%$ belong to third-order and above with $>3$ years of birth interval. About $45 \%$ of children belonged to other backward classes followed by other classes (22\%), and scheduled castes (18\%). About $46 \%$ of children were from wealthier households (richer and richest quintile) compared to the children in poor households (31\%). The majority of children residing in rural areas (59\%). The summary statistics of the variables used in the macro-level analyses are specified in Appendix Table 2.

\subsection{CFI coverage}

Figure 4 and Appendix Table 3 presents the unadjusted bivariate distribution of CFI coverage by the maternal health care service utilisation index, socio-economic status, and region of residence. The results suggest that the CFI coverage was higher among children with mothers who received a "high" maternal health care utilisation index $(62 \%)$ than those who received "low" maternal health care service utilisation (47\%). The CFI coverage was also higher among women who registered their pregnancy and also obtained an MCP card (55\%) than their counterparts (38\%). The CFI increased with an increase in the educational level of the mothers. The CFI was highest among children with lower birth order and lower birth intervals compared to their counterparts. The CFI was highest among scheduled tribes (55\%) followed by other backward classes (51\%), scheduled castes (51\%), and other castes (48\%). Again, in contrast to the exiting notion, the proportion of female children (52\%) who received full immunisation is slightly higher than male children (49\%). The percentage of CFI in the richest wealth quintile households was two times higher (62\%) compared to their poorest counterparts $(26 \%)$.

However, the regional variations in CFI are prominent with both Dry areas (34\%) and Kachchh (45\%) performing poorly in comparison to the developed regions of Saurashtra (55\%), 
181 Southeastern (51\%) and Plains (51\%). Figure 5 displays differences between the northern and 182 southern parts of Gujarat in CFI coverage. The southern districts of Tapi (73\%), Navsari (79\%), and Jamnagar (71\%) account for the higher coverage of CFI, while Vadodara, Anand, Narmada, and Porbandar account for $60 \%$ to $70 \%$. On the other hand, the northern districts of Patan (31\%), Bane's Kantha (35\%), Kachchh (45\%), and eastern districts of Panchmahal (30\%), Kheda (40\%) show a lower uptake of CFI. The district of Dohad stands at the bottom with CFI coverage of $33 \%$.

\subsection{Defining factors of CFI}

The adjusted demand and supply-side factors of CFI coverage in Gujarat based on the multivariate logistic regression model are presented in Table 2. The result demonstrates that mothers who have "high" maternal health care utilisation index have higher odds of achieving $\mathrm{CFI}(\mathrm{OR}=1.59,95 \% \mathrm{CI} 1.10-2.26)$ than those who have received "low" and "medium" utilisation index. The likelihood of children being fully immunised was almost double for mothers who have registered their pregnancy and hold an $\mathrm{MCP}$ card $(\mathrm{OR}=1.97,95 \% \mathrm{CI} 1.48$ 2.60) than those who did not register their pregnancy and MCP card. The household's economic status was statistically the most significant factor for CFI coverage in the state. Children who belonged to richer $(\mathrm{OR}=4.33,95 \%$ CI 2.67-7.01) and richest $(\mathrm{OR}=6.59,95 \% \mathrm{CI} 3.75-11.55)$ wealth quintile households received significantly higher CFI coverage than the poorer $(\mathrm{OR}=$ 2.12) and poorest counterparts $(\mathrm{OR}=1.00)$. Surprisingly, compared to urban areas the odds of CFI coverage were higher in rural areas $(\mathrm{OR}=1.35,95 \% \mathrm{CI} 1.01-1.81)$.

OLS regression estimates presented in model 1 to 5 in Table 3 shows supply and demand factors associated with CFI in Gujarat. The estimates in the model 1 considering only maternal and supply-side factors reveals that Postnatal Care (PNCs) within 2 days for the child $(\beta=0.712$, $\mathrm{p}<0.05)$ is the defining factors for the uptake of CFI. Model 2 shows that the district-level poverty ratio $(\beta=-2.513, \mathrm{p}<0.05)$ and proxy for gender discrimination defined through sex ratio at birth $(\beta=0.161, \mathrm{p}<0.10)$ are the significant factors in determining CFI levels. The estimates in model 4 and 5 indicate that institutional delivery, PNCs within 2 days for child and schedule tribe affiliation is positively associated, while fertility levels and poverty negatively associated with CFI. However, the key supply-side factors such as the health infrastructure index are not statistically significant, although positively associated with CFI. 


\section{Discussion}

Immunisation is one of the essential means to reduce child morbidity and mortality associated with infectious diseases worldwide. In India, there has been an improvement in the CFI coverage, but is still far behind the levels needed to achieve universal coverage. State and district level disparities in CFI coverage have been significant in India [7]. Considering these, in 2014 the Government of India launched a targeted intervention Mission Indradhanush, to increase coverage in low performing districts with less than 60\% CFI coverage. This mission included unvaccinated or partially vaccinated children with an aim to achieve a target of $90 \% \mathrm{CFI}$ coverage in India by 2020 [13]. However, looking at the findings from successive rounds of NFHS appears that these efforts did not make significant improvements in CFI coverage in Gujarat $[7,22]$.

The findings of the study focusing on Gujarat are intriguing and useful for policy and planning. There is a perceptible difference in the CFI between the northern and southern districts of Gujarat. The state average is significantly affected by the regional inequalities in CFI. For instance, $55 \%$ of children residing in the Saurashtra region have been immunised compared to only $34 \%$ of children in the Dry Area of Gujarat. This can be attributed to the fact that districts in southern Gujarat are more economically prosperous compared to their northern counterparts. These findings are also substantiated by previous literature highlighting that economically progressive regions have higher utilisation of $\mathrm{MCH}$ services than their counterparts in economically less progressive regions in the state $[14,18,22,26]$. The factors significantly associated with the low coverage of CFI are poor quality of maternity care, non-registration of pregnancy with MCP card, and poor economic status of the household. Both micro and macrolevel analyses suggest that improving maternal health care services such as ANCs and postnatal care, reducing higher-order births are key in increasing CFI coverage. Our findings are consistent with the previous studies from other geographical contexts that highlighted women belonging to richer households have a higher likelihood of receiving full immunisation compared to women from poorer households [15-20]. Although CFI levels were varied by the age and education of mother, caste, and sex of the child in the bivariate analyses, they are not significant in the multivariate statistical models after adjusting the effect of other factors. 
The findings of this study based on a large-scale survey differ from some of the existing evidence-based on smaller studies. For instance, a few micro studies suggest that the exclusion of marginalised communities such as the migrants, Dalits (the lowest social group in the Indian caste hierarchy) and people in remote areas facing discrimination, resulted in low CFI coverage $[27,6]$ while untouchability practices against the Dalits and lower castes also transcend into poor delivery of healthcare facilities into these communities [27]. However, our study did not find caste-wise differences in CFI coverage in Gujarat. In fact, the CFI coverage was higher in the scheduled tribe and scheduled castes (lowest social groups in Hindu caste hierarchy), in rural areas than non-scheduled castes and urban areas. There could be two possibilities for such differences and contradiction: Firstly, large scale surveys like NFHS might not reveal underpinning socio-economic forces influencing immunisation coverage due to inadequate indepth investigation of social determinants in national surveys. Secondly, small-scale surveybased studies reporting caste disparities in CFI coverage were localised and unable to provide state-level determinants. Thus, caste may still play an important role at the local level, but at the state level that influence is overridden by economic factors, i.e. households living in poorer areas are less likely to receive immunisation. Contradicting findings on caste-wise disparities from existing evidence suggest a need for a more in-depth study on the social disparity and the contextual cultural dynamics that exist across the state of Gujarat.

The existing evidence suggests that even though health averages in urban areas are above their rural counterparts, there are also places of social disadvantage within urban areas (e.g. urban slum and peri-urban areas) that characterised as zones of increased public health risks [29, 30]. In rural areas of Gujarat or other states of India, tracing, reaching and coverage of children who needed immunisation is easy because of well-established channels of public health care delivery, especially a strong presence of frontline health workers after the commencement of National Rural Health Mission [30]. However, the low coverage of immunisation in urban areas where the private sector is dominant needs further investigation, especially to understand the hindrances in reaching services to disadvantaged populations. often state-specific geographies, health, and social systems influence the performance of the programme. The state of Gujarat is unique in terms of operating the Private-Public Partnerships (PPP) model in the provision of $\mathrm{MCH}$ care [28]. Around $98 \%$ and $89 \%$ of the children getting immunisation from a public source in rural and urban areas respectively (Figure 6). Despite the PPP model in place, the share of 
272 private-sector immunisation (11\%) in Gujarat is much less than Tamil Nadu, Karnataka,

273 Maharashtra, and Telangana (states without PPP model in place) [24]. The latest NFHS report

274 suggests that in comparison to other developed states private sector participation in institutional

275 deliveries in Gujarat is very high (where the incentive is high); however, their participation in

276 delivering all recommended types of antenatal care and postnatal care is less [7]. While our study

277 report that ANCs and PNCs emerged as defining factors for CFI coverage.

278

279 Limitation of study and need for future research

280

This study has a few limitations: First, the study failed to examine supply-side determinants of 282 CFI at the individual level due to lack of information in the NFHS dataset. An in-depth study on 283 the contribution and failure of supply-chines, from receiver and provider perspective, needs to be 284 examined. Second, the present study didn't examine how far the PPP model of MCH care is helping or hindering the vaccination coverage in children. In particular, there is a need to examine the question that whether the PPP model in MCH care making the integration of family planning, MCH care, and immunisation coverage difficult, in particular in urban areas? Third, the monitoring and evaluation process of immunisation programme of Government of India depends on four major sources of information: (1) India Health Management Information System (HMIS) reports; (2) periodic sample surveys; (3) vaccine-preventable disease surveillance; and (4) concurrent routine immunisation monitoring based on a mobile application for data collection

292 [31-35]. Considering the mismatch in the estimates across the different sources of information on 293 CFI and the resultant state rankings (Figure 7), there is a greater need to investigate data-linkages 294 and triangulation methodologies for more robust estimations of CFI. Such investigations 295 undoubtedly help to recognise limitation and shortcomings in the scientific treatment of multiple data sources on this subject and the care and caution required in triangulating and validating them across sources. Fourth, this study did not compare the national ranking of the Gujarat and

298 its districts on the multiple definitions used to measure the CFI. For instance, to understand 299 immunisaiton coverage for the 2nd year of life, UNICEF Multiple Indicator Cluster Surveys 300 (MICS) examines children aged 24 to 35 months. Also, Mission Indradhanush (MI) programme measures full immunisaiton coverage of children in the age group 0-11 months and 9-11 months, alongside 12-23 months. The current study used CFI estimates for the age group 12-23 months. 
Finally, under its Universal Immunisation Programme (UIP) Government of India recently included additional vaccines [36] which were not considered in the definition of CFI used by the current study. However, for this study, we have adopted a widely used and cross-country comparable definition for measuring CFI: CFI in the age of 12-23 months from NFHS. Unlike the official statistics, the survey estimates like NFHS (as a part of the DHS family) have an immense advantage for international comparison considering the uniform survey design. Also, the micro-data allows for making a more robust assessment of the socioeconomic disparities and determinants of CFI. In that sense, our paper assumes significance for policy and practice.

\section{Conclusions}

The coverage of children full immunisation in Gujarat is the second-lowest in India. The targeted intervention, Mission Indradhanush-2.0 of the Government of India should focus on the economically backward northern districts and poorer households in Gujarat. Similarly, maternal health care services including various ANC and PNC components should be improved in the poorer districts and households. Mothers with higher-order births and urban households need an additional push for the immunisation of their children.

Furthermore, considering the economic barrier as a major defining factor of CFI in Gujarat, the study advance that state needs to spend more on its health care, especially for the provision of all required vaccinations to children. Gujarat budgetary allocations for health care services has been reducing over the years. The state spends less than one percent of its Gross State Domestic Product on health care, and its revenue public health outlays are one of the lowest in India which can have huge implications for highly publicly provided services such as vaccination for children. A recent report of Controller Audit General (CAG) suggests that the state utilised only $79 \%$ of the amount allocated for building health infrastructure [37]. Probably this is the reason why HII does not emerge as a significant variable in this study.

\section{Funding}

This research is funded by the Department of Biotechnology (DBT) India and Medical Research Council (MRC) UK (PAC-SSS-KSJ-DBT-03180321-1114). The final decisions on the study design, analysis, the decision to publish, and the content of the manuscript were made by the 
331 University-based researchers. The funding bodies had no role in study design, data collection, 332 and analysis.

333 Availability of data and materials

334 The first author lodged a request application via the online Demographic and Health Surveys 335 program to use NFHS data (2015-2016) for this study. The dataset is available at https://dhsprogram.com/data/dataset/India_Standard-DHS_2015.cfm?flag=0

\section{Ethics approval and consent to participate}

This study is a secondary analysis of the NFHS data. The NFHS obtained ethical clearance from the Ethical Review Board of Indian Council for Medical Research (ICMR), ICF Institutional Review Board, IIPS and Centre for Disease Control. Data for this study are free to download and use by completing a request application via the online DHS program (https://dhsprogram.com). The NFHS received informed consent from all the study participants before preceding to the 344 survey.

Conflict of Interest Statement: None declared

\section{References}

[1] Duclos P, Okwo-Bele JM, Gacic-Dobo M, Cherian T. Global immunization: status, progress, challenges, and future. BMC international health and human rights. 2009 Oct;9 (1):S2.

[2] WHO and UNICEF. Immunisation Summary: A statistical reference containing data through 2011. UNICEF Statistics and Monitoring Section Division of Policy and Practice. New York. USA 2013. https://www.unicef.org/Immunisation/files/EN-ImmSumm-2013.pdf.

[3] Casey RM, Hampton LM, Anya BP, Gacic-Dobo M, Diallo MS, Wallace AS. State of equity: childhood immunization in the World Health Organization African Region. The Pan African medical journal. 2017;27 (Suppl 3).

357 [4] Asia WW. Expanded Programme on Immunization (EPI) REGIONAL FACT SHEET 2017. World Heal Organ. 2017; 6:1-98. 
359 [5] Das RK, Dasgupta P. Child Health and Immunisation: A Macro-Perspective. Economic and 360 Political Weekly. 2000 Feb 26:645-55.

361 [6] Montgomery JP, Ganguly P, Carlson BF, Shrivastwa N, Boulton ML. An evaluation of 362

[13] WHO; https://www.who.int/data/gho/indicator-metadata-registry/imr-details/3317 immunization services, using the reaching every district criteria, in two districts of Gujarat, India. Global health research and policy. 2018 Dec; 3(1):5.

[7] International Institute for Population Sciences (IIPS) and ICF. National Family Health Survey (NFHS-4), 2015-16: India.

[8] Directorate of Economics and Statistics. Socio-economic review, Gujarat state, 2017-18, Government of Gujarat, Gandhinagar.

[9] Office of the Registrar General \& Census Commissioner (2011), Provisional Population Tables: India, Ministry of Home Affairs, Government of India. http://censusindia.gov.in/2011-prov-results/prov_rep_tables.html

[10] Rural Health Statistics, district-wise health care infrastructure in India, Ministry of Health and Family Welfare, Government of India.

[11] Reserve Bank of India, Handbook of Statistics on the Indian Economy. https://www.rbi.org.in/Scripts/AnnualPublications.aspx?head=Handbook\%20of\%20Stati stics\%20on\%20Indian\%20Economy.

[12] Colin, Cameron A., and Pravin Trivedi. "Microeconometrics Using Stata, Revised Edition." (2010).

[14] Ghosh A, Laxminarayan R. Demand-and supply-side determinants of diphtheria-pertussistetanus nonvaccination and dropout in rural India. Vaccine. 2017 Feb 15; 35(7):1087-93.

[15] Fatiregun, Akinola Ayoola, and Anselm O. Okoro. "Maternal determinants of complete child immunization among children aged 12-23 months in a southern district of Nigeria." Vaccine 30, no. 4 (2012): 730-736. 
[16] Schoeps, A., N. Ouedraogo, M. Kagone, A. Sie, O. Müller, and H. Becher. "Sociodemographic determinants of timely adherence to BCG, Penta3, measles, and complete vaccination schedule in Burkina Faso." Vaccine 32, no. 1 (2013): 96-102.

[17] Kawakatsu, Yoshito, and Sumihisa Honda. "Individual-, family-and community-level determinants of full vaccination coverage among children aged 12-23 months in western Kenya." Vaccine 30, no. 52 (2012): 7588-7593.

[18] Arokiasamy P, Pradhan J. Maternal health care in India: access and demand determinants. Primary health care research \& development. 2013 Oct;14(4):373-93.

[19] Mbengue MA, Sarr M, Faye A, Badiane O, Camara FB, Mboup S, Dieye TN. Determinants of complete immunization among senegalese children aged 12-23 months: evidence from the demographic and health survey. BMC public health. 2017 Dec;17(1):630.

[20] Lakew Y, Bekele A, Biadgilign S. Factors influencing full immunization coverage among 12-23 months of age children in Ethiopia: evidence from the national demographic and health survey in 2011. BMC public health. 2015 Dec;15(1):728.

[21] Kotelchuck, Milton. "An evaluation of the Kessner adequacy of prenatal care index and a proposed adequacy of prenatal care utilization index." American journal of public health 84, no. 9 (1994): 1414-1420.

[22] Singh, Prashant Kumar. "Trends in child immunization across geographical regions in India: focus on urban-rural and gender differentials.” PloS one vol. 8,9 e73102. 4 Sep. 2013, doi:10.1371/journal.pone.0073102

[23] UNDP, HDR. "Human Development Report 2015 Technical notes." (2015).

[24] Ministry of Statistics \& Programme Implementation. 2018. Household social consumption in India: Health NSS 75th round (July, 2017 - June, 2018), Government of India. http://www.mospi.gov.in/sites/default/files/publication_reports/KI_Health_75th_Final.p df.

[25] Government of India. Mission Indradhansush national and state factsheets. 2019; Accessed January: https://www.nhp.gov.in/mission-indradhanush1_pg 
411 [26] Puri, P., Khan, J., Shil, Ali, M. A cross-sectional study on selected child health outcomes in India: Quantifying the spatial variations and identification of the parental risk factors, Scientific Reports, 10:6645, 2020

[27] East-West Management Institute, Navsarjan Trust. (2013). Blindspots to the polio eradication endgame: measuring the limitations of polio vaccination delivery in Dalit communities in Gujarat. http://questforequity.org/contents/Papers/Blind\%20Spots\%20to\%20the\%20Polio\%20Eradicatio n\%20Endgame\%20Measuring\%20the\%20Limitations\%200f\%20Polio\%20Vaccination\%20Delivery\%20among \%20Dalits\%20in\%20Gujarat,\%20Navsarjan\%20Trust..pdf

[28] Mavalankar D, Singh A, Patel SR, Desai A, Singh P V. Saving mothers and newborns through an innovative partnership with private sector obstetricians: Chiranjeevi scheme of Gujarat, India. Int J Gynecol Obstet. International Federation of Gynecology and Obstetrics; 2009; 107: 271-276. pmid:19846090

[29] Grundy, J., Wang, X., Hirabayashi, K.C., Duncan, R., Bersonda, D., Eltayeb, A.O., Mindra, G. and Nandy, R., 2019. Health and immunisation services for the urban poor in selected countries of Asia. Infectious diseases of poverty, 8(1), p.26.

[30] UNICEF EAPRO. Thematic Analysis - Health and Immunization Services for the Urban Poor in East Asia: UNICEF EAPRO; 2017. https://www.unicef.org/health/files/P2_thematic_analysis_Health_and_Immunization_fo r_the_Urban_Poor_in_East_Asia.pdf. Accessed 3 Apr 2019.

[31] Ministry of Health and Family Welfare (MOHFW), Statistics Division. Rural Health Statistics, Government of India, 2018-2019. https://main.mohfw.gov.in/sites/default/files/Final\%20RHS\%202018-19_0.pdf

[32] Gurnani, V., Haldar, P., Aggarwal, M.K., Das, M.K., Chauhan, A., Murray, J., Arora, N.K., Jhalani, M. and Sudan, P., 2018. Improving vaccination coverage in India: lessons from Intensified Mission Indradhanush, a cross-sectoral systems strengthening strategy. bmj, 363. 
439 [33] Ministry of Health and Family Welfare (MOHFW). Intensified Mission Indradhanush,

440

441

442

443

444 445

446

447

448

449

450

451

452 operational guidelines. MOHFW, 2017. https://mohfw.gov.in/sites/default/files/Mission\%20Indradhanush\%20Guidelines.pdf

[34] Ministry of Health and Family Welfare. Coverage Evaluation Survey- Intensified Mission Indradhanush. MOHFW, 2018.

[35] Ministry of Health and Family Welfare. United Nations Development Programme, Global alliance for vaccine initiative. E-VIN Tracking Database, October 2017 -April 2018. Delhi, India: MOHFW; 2018 http://www.in.undp.org/content/india/en/home/operations/projects/health/evin.html

[36] Newtonraj, A. "India's fight against vaccine-preventable diseases; newer changes and challenges." Journal of Medical Society 33, no. 1 (2019): 64-64.

[37] Bridge India, Briefing: Public health in Gujarat, October 22, 2018, https://www.bridgeindia.org.uk/briefing-public-health-in-gujarat/ 
Table 1

Descriptive statistics of the study population, Gujarat, India, 2015-16 ( $n=7730)$.

\begin{tabular}{|c|c|c|c|c|c|}
\hline Variables & $\begin{array}{l}\text { Categories/Value } \\
\text { labels }\end{array}$ & Frequency & $\begin{array}{l}\text { Sample } \\
\text { distribution } \\
\text { (Percent) }\end{array}$ & $\begin{array}{l}\text { Lower } \\
\text { limit }\end{array}$ & $\begin{array}{l}\text { Upper } \\
\text { limit }\end{array}$ \\
\hline \multirow{3}{*}{$\begin{array}{l}\text { Level of MCH care service } \\
\text { utilisation }\end{array}$} & Low $^{\mathrm{a}}$ & 6217 & 81.20 & 80.45 & 81.93 \\
\hline & Medium & 705 & 8.82 & 8.30 & 9.37 \\
\hline & High & 808 & 9.98 & 9.42 & 10.56 \\
\hline \multirow{2}{*}{$\begin{array}{l}\text { Pregnancy registered with MCP } \\
\text { Card }\end{array}$} & Yes & 3204 & 42.03 & 41.10 & 42.97 \\
\hline & $\mathrm{No}^{\mathrm{b}}$ & 4526 & 57.97 & 57.03 & 58.90 \\
\hline \multirow{3}{*}{ Mother's age } & 15-24 Years & 2665 & 32.03 & 31.15 & 32.92 \\
\hline & 25-29 Years & 2910 & 39.09 & 38.17 & 40.02 \\
\hline & 30 years and above & 2155 & 28.88 & 28.03 & 29.75 \\
\hline \multirow[t]{4}{*}{ Level of mother's education } & No education & 1943 & 23.48 & 22.69 & 24.29 \\
\hline & Primary & 1256 & 15.22 & 14.55 & 15.91 \\
\hline & Secondary & 3942 & 51.85 & 50.90 & 52.80 \\
\hline & Higher & 589 & 9.45 & 8.91 & 10.02 \\
\hline \multirow[t]{3}{*}{ Sex of the child } & Male & 4038 & 52.69 & 51.75 & 53.64 \\
\hline & Female & 3692 & 47.31 & 46.36 & 48.25 \\
\hline & Order 1 and $<2$ years & 1097 & 13.93 & 13.29 & 14.60 \\
\hline \multirow{10}{*}{$\begin{array}{l}\text { The intersection of birth order and } \\
\text { birth interval }\end{array}$} & Order 1 and 2-3 years & 910 & 12.79 & 12.17 & 13.44 \\
\hline & Order 1 and $>3$ years & 1092 & 14.59 & 13.93 & 15.27 \\
\hline & Order 2 and $<3$ years & 1386 & 17.17 & 16.47 & 17.90 \\
\hline & Order 2 and $>3$ years & 1092 & 14.66 & 14.00 & 15.34 \\
\hline & Order 3 and $<3$ years & 669 & 8.39 & 7.88 & 8.93 \\
\hline & Order 3 and $>3$ years & 487 & 6.43 & 5.98 & 6.91 \\
\hline & $\begin{array}{l}\text { Order } 3+\text { and }<3 \\
\text { years }\end{array}$ & 553 & 6.57 & 6.11 & 7.05 \\
\hline & $\begin{array}{l}\text { Order } 3+\text { and }>3 \\
\text { years }\end{array}$ & 369 & 4.57 & 4.19 & 4.98 \\
\hline & Not reported /missing & 75 & 0.90 & 0.74 & 1.10 \\
\hline & $\mathrm{SC}$ & 844 & 11.21 & 10.62 & 11.82 \\
\hline \multirow[t]{5}{*}{ Social group } & ST & 1975 & 17.69 & 16.98 & 18.42 \\
\hline & $\mathrm{OBC}$ & 3274 & 44.70 & 43.76 & 45.64 \\
\hline & Others & 1346 & 21.79 & 21.02 & 22.58 \\
\hline & No stated & 291 & 4.62 & 4.24 & 5.03 \\
\hline & Hindu & 6894 & 89.90 & 89.31 & 90.45 \\
\hline \multirow[t]{2}{*}{ Religion $^{c}$} & Muslim & 737 & 10.10 & 9.55 & 10.69 \\
\hline & Poorest & 1140 & 10.71 & 10.14 & 11.31 \\
\hline \multirow[t]{5}{*}{ Wealth quintile } & Poorer & 1804 & 20.17 & 19.42 & 20.94 \\
\hline & Middle & 1852 & 23.57 & 22.78 & 24.39 \\
\hline & Richer & 1574 & 22.45 & 21.67 & 23.25 \\
\hline & Richest & 1360 & 23.10 & 22.31 & 23.91 \\
\hline & Urban & 2507 & 40.56 & 51.75 & 53.64 \\
\hline \multirow[t]{2}{*}{ Place of residence } & Rural & 5223 & 59.44 & 46.36 & 48.25 \\
\hline & Kachchh & 323 & 3.95 & 3.59 & 4.33 \\
\hline \multirow[t]{5}{*}{ Geographical regions } & Dry Areas & 714 & 8.39 & 7.88 & 8.93 \\
\hline & Plain Northern & 1730 & 29.84 & 28.98 & 30.71 \\
\hline & Saurashtra & 1888 & 21.88 & 21.10 & 22.67 \\
\hline & South Eastern & 3075 & 35.95 & 35.05 & 36.86 \\
\hline & Total & 7730 & 100.00 & - & - \\
\hline
\end{tabular}


a Those who have not visited any ANC facility have been considered under the poor quality of maternity care.

${ }^{\mathrm{b}}$ Not reported and missing has been considered as no MCP card with pregnancy registration.

${ }^{c}$ Other religion groups $(n=29)$ dropped due to insufficient samples for analysis.

\section{Table 2}

Logistic regression estimates: Factors associated with children full immunization, Gujarat, India, 201516

\begin{tabular}{|c|c|c|c|c|}
\hline \multirow{2}{*}{ Predictors } & & \multicolumn{3}{|c|}{ Children Full Immunization } \\
\hline & & Odds Ratio & Lower limit & Upper limit \\
\hline \multicolumn{5}{|c|}{$\begin{array}{l}\text { Level of MCH care service } \\
\text { utilisation }\end{array}$} \\
\hline & Low & 1.00 & & \\
\hline & Medium & $1.76^{* * *}$ & 1.22 & 2.52 \\
\hline & High & $1.59^{* *}$ & 1.11 & 2.27 \\
\hline \multicolumn{5}{|c|}{$\begin{array}{l}\text { Pregnancy registered } \\
\text { with MCP Card }\end{array}$} \\
\hline & No & 1.00 & & \\
\hline & Yes & $1.97 * * *$ & 1.49 & 2.61 \\
\hline \multicolumn{5}{|c|}{ Sex of the child } \\
\hline & Male & 1.00 & & \\
\hline & Female & 1.13 & 0.90 & 1.42 \\
\hline \multicolumn{5}{|c|}{ Mother's age } \\
\hline & $15-24$ years & 1.00 & & \\
\hline & $25-29$ years & 0.98 & 0.74 & 1.31 \\
\hline & 30 years \& above & 1.15 & 0.79 & 1.69 \\
\hline \multicolumn{5}{|c|}{$\begin{array}{l}\text { Mother's education } \\
\text { level }\end{array}$} \\
\hline & No education & 1.00 & & \\
\hline & Primary & 1.14 & 0.79 & 1.67 \\
\hline & Secondary & 1.09 & 0.79 & 1.50 \\
\hline & Higher \& above & 1.04 & 0.58 & 1.85 \\
\hline \multicolumn{5}{|c|}{$\begin{array}{l}\text { Intersection of birth order } \\
\text { and birth interval }\end{array}$} \\
\hline & Order $1 \&<2$ years & 1.00 & & \\
\hline & Order $1 \& 2$-3years & $0.52^{* * *}$ & 0.33 & 0.83 \\
\hline & Order $1 \&>3$ years & 0.76 & 0.48 & 1.19 \\
\hline & Order $2 \&<3$ years & $0.56^{* * *}$ & 0.38 & 0.85 \\
\hline & Order $2 \&>3$ years & $0.46^{* * *}$ & 0.29 & 0.73 \\
\hline & Order $3 \&<3$ years & $0.44^{* * *}$ & 0.26 & 0.74 \\
\hline & Order $3 \&>3$ years & 0.60 & 0.33 & 1.11 \\
\hline & Order $>3 \&<3$ years & $0.46^{* *}$ & 0.25 & 0.84 \\
\hline & Order $>3 \&>3$ years & 0.73 & 0.37 & 1.42 \\
\hline & $\begin{array}{l}\text { Not } \\
\text { reported/missing }\end{array}$ & 1.23 & 0.23 & 6.65 \\
\hline \multicolumn{5}{|c|}{ Social group } \\
\hline & Scheduled castes & 1.00 & & \\
\hline & Scheduled tribes & 1.47 & 0.93 & 2.34 \\
\hline & $\begin{array}{l}\text { Other backward } \\
\text { class }\end{array}$ & 0.94 & 0.64 & 1.38 \\
\hline & Others & 0.77 & 0.49 & 1.21 \\
\hline & $\begin{array}{l}\text { Not } \\
\text { reported/missing }\end{array}$ & 0.59 & 0.30 & 1.17 \\
\hline
\end{tabular}




\begin{tabular}{|c|c|c|c|c|}
\hline \multicolumn{5}{|l|}{ Religion } \\
\hline & Hindu & 1.00 & & \\
\hline & Muslim & 0.78 & 0.52 & 1.15 \\
\hline \multicolumn{5}{|l|}{ Wealth quintile } \\
\hline & Poorest & 1.00 & & \\
\hline & Poorer & $2.12^{* * *}$ & 1.40 & 3.20 \\
\hline & Middle & $2.95^{* * *}$ & 1.90 & 4.57 \\
\hline & Richer & $4.33^{* * *}$ & 2.68 & 7.01 \\
\hline & Richest & $6.59^{* * *}$ & 3.75 & 11.55 \\
\hline \multicolumn{5}{|l|}{ Place of residence } \\
\hline & Urban & 1.00 & & \\
\hline & Rural & $1.35^{* *}$ & 1.01 & 1.82 \\
\hline \multicolumn{5}{|l|}{ Geographical region } \\
\hline & Kachchh & 1.00 & & \\
\hline & Dry Areas & 0.66 & 0.33 & 1.35 \\
\hline & Plains Northern & 1.11 & 0.59 & 2.08 \\
\hline & Saurashtra & 1.33 & 0.71 & 2.48 \\
\hline & South Eastern & 1.20 & 0.64 & 2.26 \\
\hline Constant & & $0.20^{* * *}$ & 0.08 & 0.47 \\
\hline Number of observations & & 1394 & & \\
\hline LR $\operatorname{chi} 2(26)$ & & 188 & & \\
\hline Prob.> chi2 & & 0.000 & & \\
\hline Pseudo R2 & & 0.098 & & \\
\hline
\end{tabular}

Note: Significance levels: $* * * \mathrm{p}<0.01, * * \mathrm{p}<0.05, * \mathrm{p}<0.1$ 


\section{Table 3}

Ordinary least square regression estimates: Supply and demand-side factors associated with children full immunisation in Gujarat

\begin{tabular}{|c|c|c|c|c|c|}
\hline VARIABLES & Model & Model & Model & Model & Model \\
\hline & $(1)$ & $(2)$ & $(3)$ & $(4)$ & $(5)$ \\
\hline Four or more ANCs & 0.112 & & & -0.139 & -0.0726 \\
\hline & $(0.237)$ & & & $(0.195)$ & $(0.192)$ \\
\hline Institutional delivery & 0.261 & & & $0.727 *$ & $0.449 *$ \\
\hline & $(0.313)$ & & & $(0.345)$ & $(0.253)$ \\
\hline PNCs within 2 days for Child & $0.712 * *$ & & & $0.644 * *$ & 0.510 \\
\hline & $(0.293)$ & & & $(0.299)$ & $(0.360)$ \\
\hline Health Infrastructure Index & 0.00787 & & & 0.0333 & -0.00862 \\
\hline & $(0.0425)$ & & & $(0.0606)$ & $(0.0575)$ \\
\hline Mean children ever born & & & & $-29.44 *$ & $-38.23 * * *$ \\
\hline & & & & $(16.60)$ & $(10.25)$ \\
\hline Child marriages & & 0.0937 & & & \\
\hline & & $(0.306)$ & & & \\
\hline Modern contraception use & 0.338 & & & & 0.317 \\
\hline & $(0.374)$ & & & & $(0.330)$ \\
\hline Sex ratio at birth & & $0.161 *$ & & & 0.0993 \\
\hline & & $(0.0865)$ & & & $(0.0601)$ \\
\hline Literacy rate & & -0.355 & & & \\
\hline & & $(0.786)$ & & & \\
\hline $\mathrm{SC}$ & & -1.582 & -0.196 & 0.213 & -0.763 \\
\hline & & (1.706) & $(0.882)$ & $(0.811)$ & (1.221) \\
\hline ST & & 0.256 & $0.404 * *$ & $0.498 * * *$ & 0.0841 \\
\hline & & $(0.194)$ & $(0.149)$ & $(0.160)$ & $(0.186)$ \\
\hline Muslim & & -0.246 & -0.464 & -0.343 & 0.208 \\
\hline & & $(0.346)$ & $(0.395)$ & $(0.351)$ & $(0.447)$ \\
\hline Urban & & -0.00649 & $-0.222 *$ & -0.0935 & \\
\hline & & $(0.179)$ & (0.128) & $(0.185)$ & \\
\hline Poverty ratio & & $-2.513 * *$ & $-2.349 * * *$ & $-2.057 * * *$ & \\
\hline & & $(0.915)$ & $(0.362)$ & $(0.587)$ & \\
\hline Constant & -7.404 & -18.63 & $101.2 * * *$ & 12.00 & -26.55 \\
\hline & (29.86) & (58.09) & (11.12) & (43.51) & $(38.43)$ \\
\hline Observations & 27 & 27 & 26 & 27 & 27 \\
\hline R-squared & 0.376 & 0.573 & 0.488 & 0.641 & 0.690 \\
\hline
\end{tabular}


Fig. 1 State-wise percentage of children fully immunised in India, 2015-16. Source: IIPS and ICF Macro (2017). Note: * Union Territories

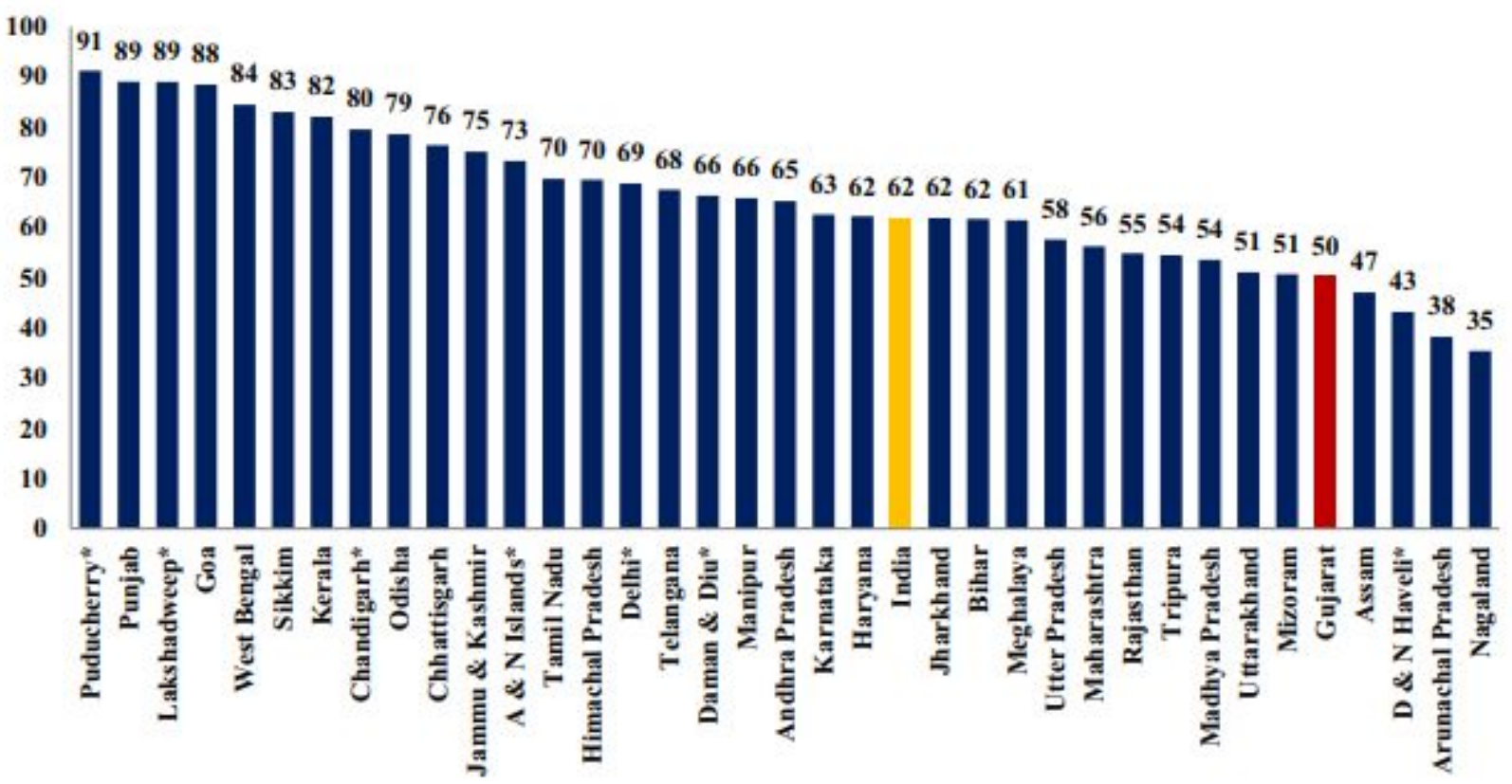

Fig. 2. Percentage of children by type of vaccination coverage in Gujarat, 2015-16. Source: IIPS and ICF Macro (2017).

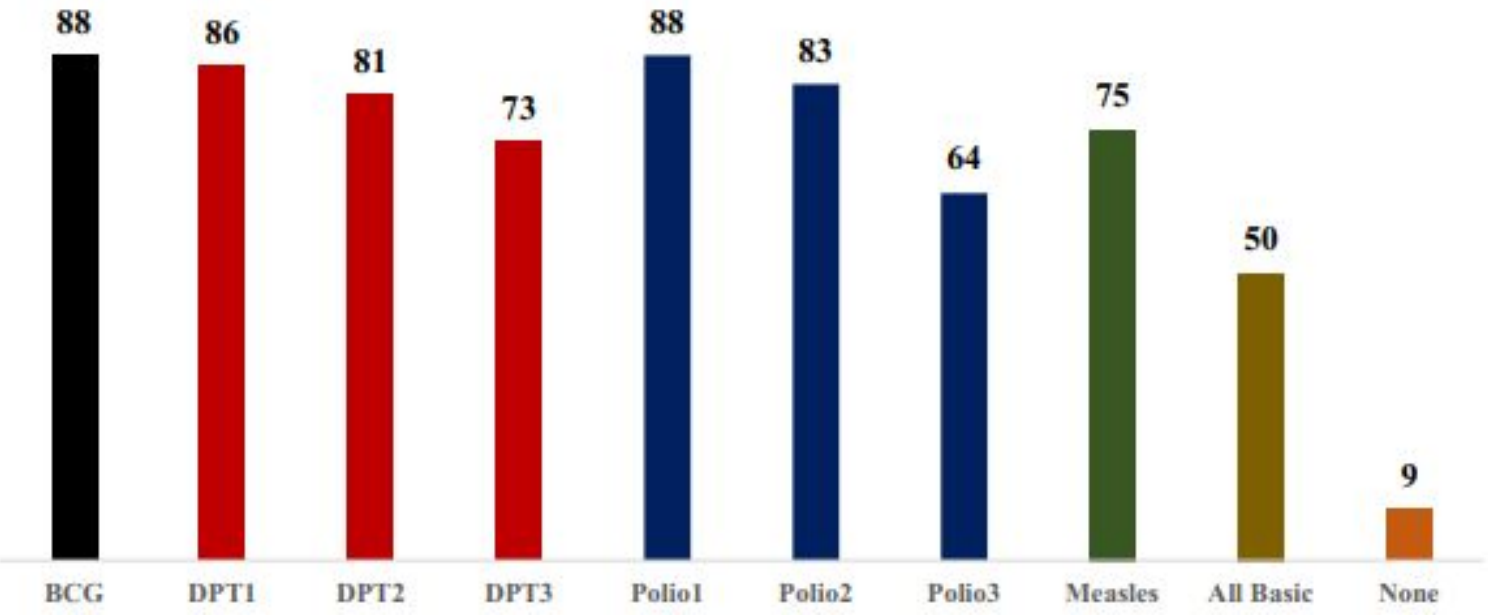


Fig. 3. Trends in children fully immunised in Gujarat during 2005-06 to 2015-16. Source: IIPS and ICF Macro (2017)

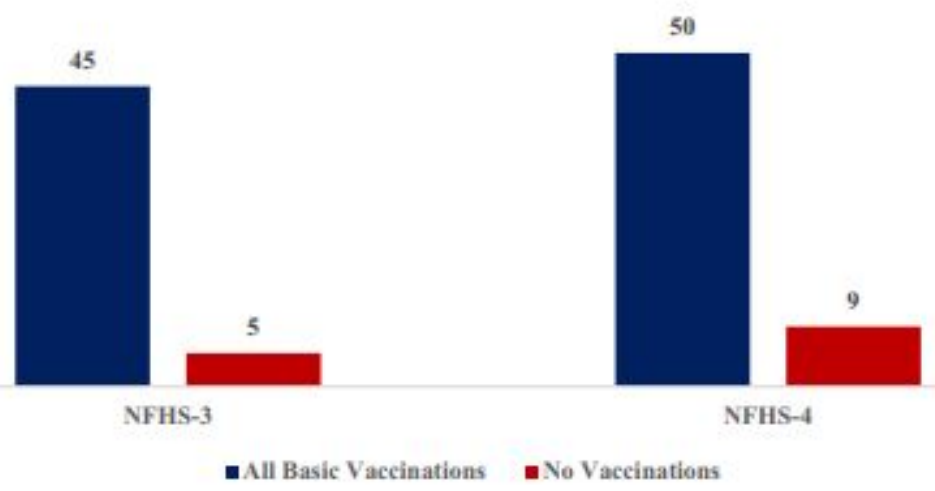


Fig.4. Percentage of children fully immunised by the level of maternal health care service utilisation and socio-economic factors in Gujarat, India, 2015-16. Source: Authors estimation.
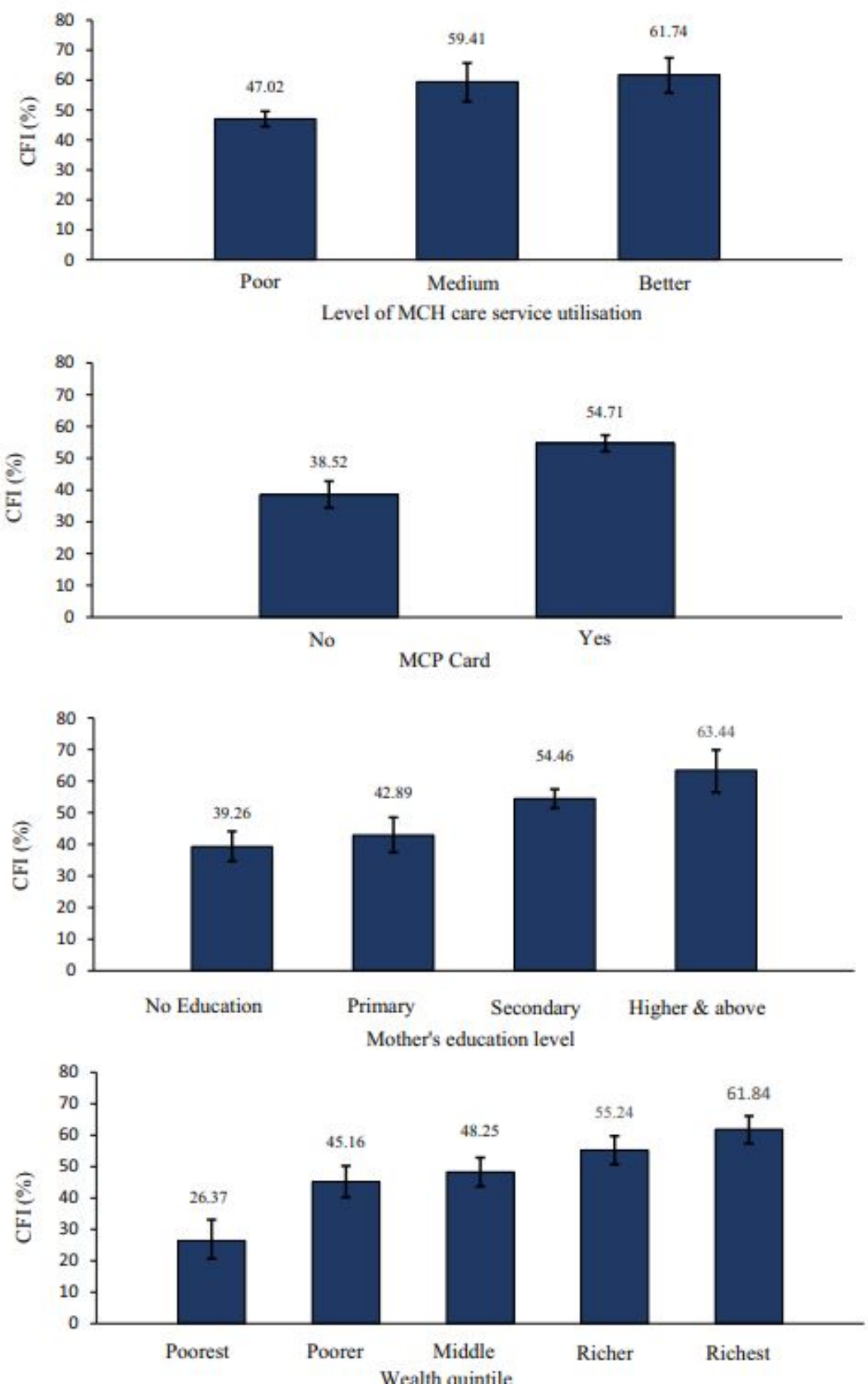
Fig. 5. District-wise percentage of children fully immunised in Gujarat, India, 2015-16. Source: Authors estimation.

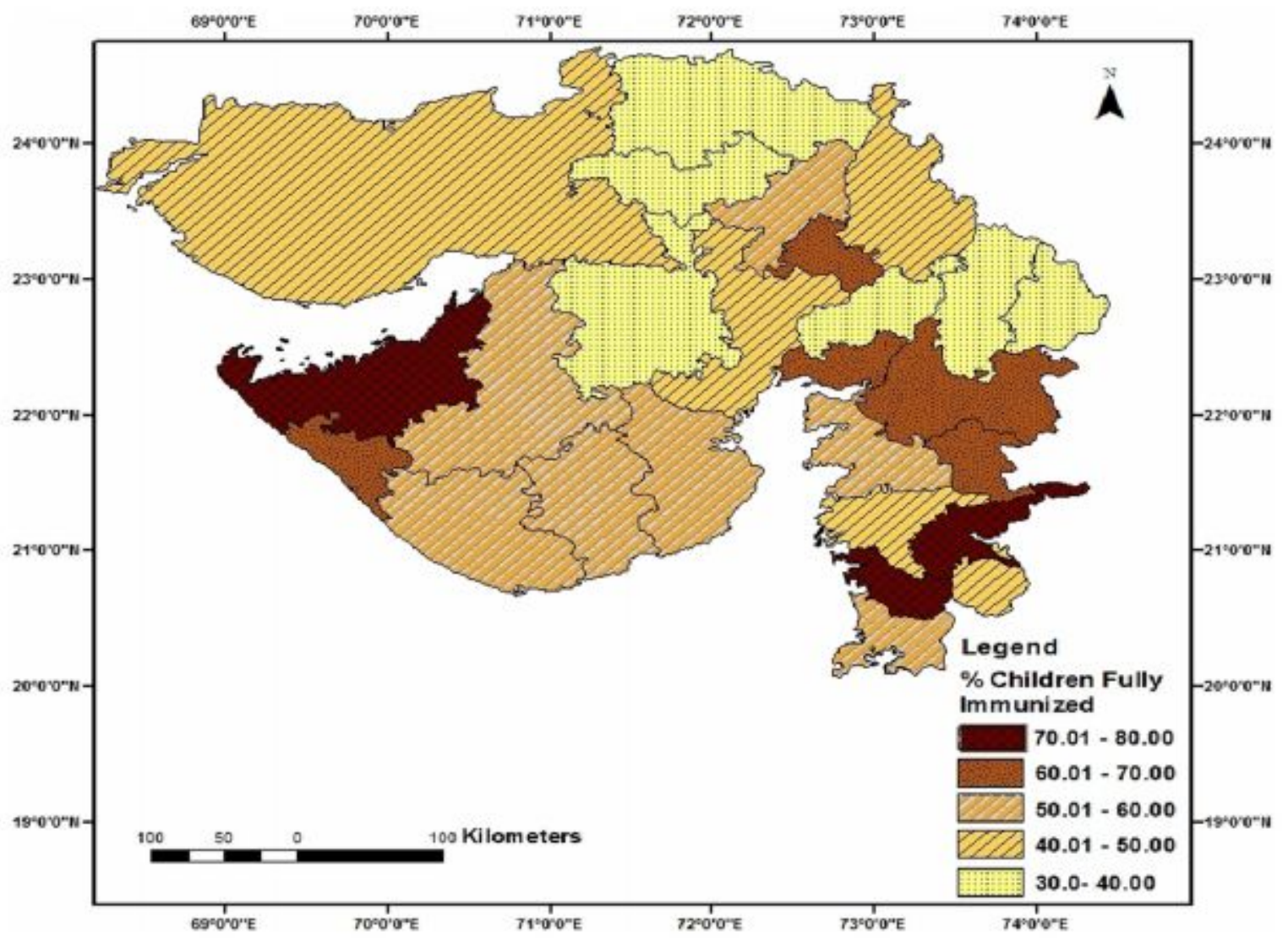

Fig. 6. Percentage break-up of children aged $0-5$ years having received any immunisation by source in rural and urban areas in Gujarat, 2017. Source: Ministry of Statistics \& Programme Implementation (2018)

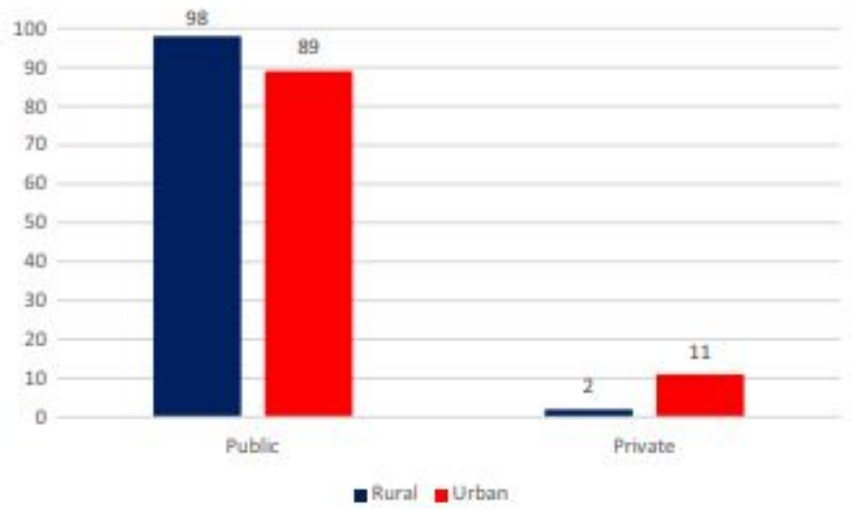


Fig. 7. State-wise percentage of children fully immunised in India from NFHS (2015-16) compared to HMIS (2015-16 and 2018-19). Source: IIPS and ICF Macro (2017); India Health Management Information System (2015-16 and 2018-19).

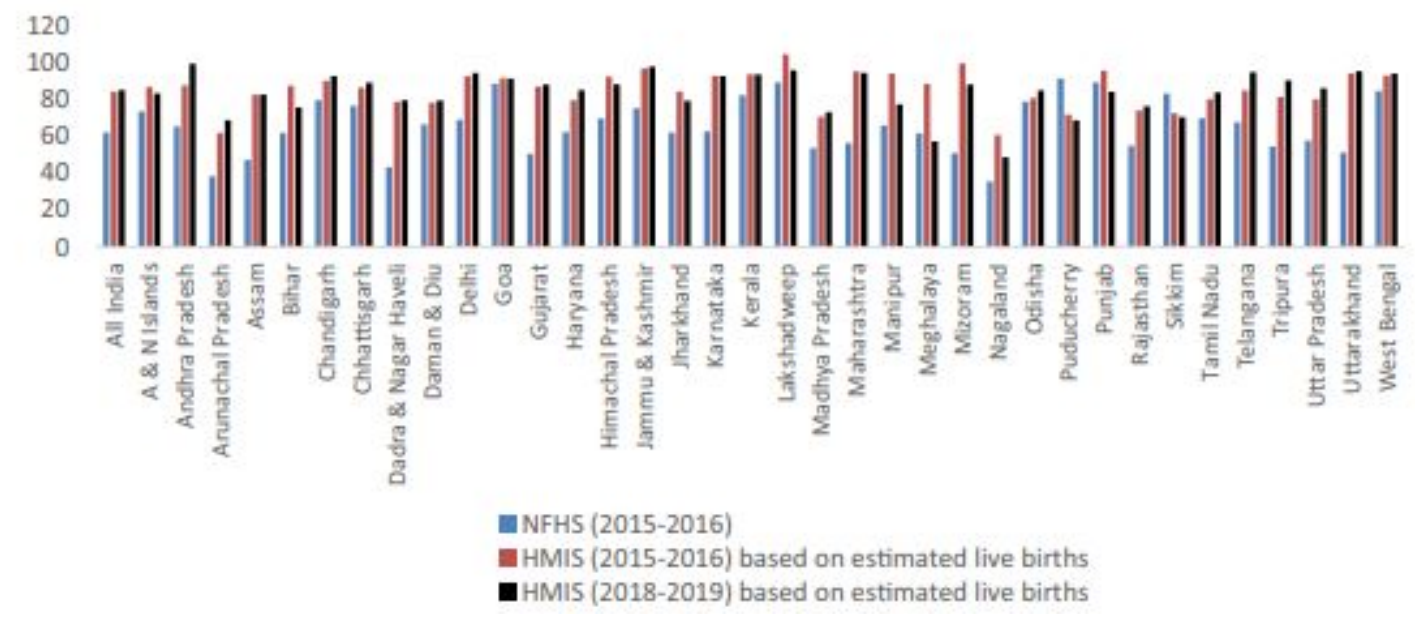

